\title{
USING A DISCRETE ELEMENT/FINITE ELEMENT APPROACH TO MODEL IMPACT OF A RIGID PROJECTILE ON CONCRETE AND REINFORCED CONCRETE TARGETS
}

\author{
ANDRIA ANTONIOU ${ }^{1}$, LAURENT DAUDEVILLE ${ }^{1}$, PHILIPPE MARIN $^{1} \&$ SERGUEI POTAPOV $^{2}$ \\ ${ }^{1}$ Université Grenoble Alpes INP/CNRS, France \\ ${ }^{2}$ IMSIA, France
}

\section{ABSTRACT}

This paper presents a mixed numerical modelling able to predict the response of reinforced concrete (RC) structures under extreme loadings such as missile impacts. Concrete is modelled using cohesive rigid spherical discrete elements (DE), while steel reinforcement is represented by beam-like finite elements (FE). Concrete-steel DEM/FEM bond model calibrated on pull-out tests is used, which ensures forces transmitting between steel and concrete. This approach is validated through the simulation of two experiments (edge-on-impact test and drop-weight impact) involving hard impacts on plain concrete and a large $\mathrm{RC}$ beam. The numerical results are presented and their comparison with the experimental data is discussed.

Keywords: DEM, steel-concrete bond model, hard impact, reinforced concrete, numerical modelling.

\section{INTRODUCTION}

Reinforced concrete (RC) shielding barriers are usually employed to protect sensitive infrastructures against the risk of extreme loading such as missile impacts. For safety reasons it is essential to assess the response of this kind of structures until their complete failure and account for their ultimate resistance capacity. Discrete element method (DEM) is appropriate to describe those advanced damaged states and fragmentation mechanisms due to its discontinuous nature.

This study proposes a mixed DEM/FEM approach able to predict damage of plain and reinforced concrete under severe impacts. It is implemented in EUROPLEXUS fast dynamics software [1]. The basic ideas of the DEM model used here are described in [2]-[4]. The DE mesh generation method uses a geometric algorithm based on a disordered assembly of rigid spherical elements proposed by Jerier et al. [5]. Steel reinforcement is modelled as beam-like elements through a standard FEM. A concrete-steel bond proposed by Potapov et al. [6] is used to manage interactions between concrete $\mathrm{DE}$ and steel rebars.

To show the capability of the DEM approach to model hard-type impacts, the simulation results of two experiments are presented: 1) the edge-on-impact test, performed by Forquin and Erzar [7] on thin plain concrete tile, and 2) a drop-weight impact test on a RC beam conducted by Saatci [8]. The numerical simulations of the two tests are analysed and compared with the experimental data.

\section{DEM/FEM REINFORCED CONCRETE MODELLING}

\subsection{Discrete element model for plain concrete}

The DEM for plain concrete is an extended version of the model for granular materials enriched by cohesive interactions [2]-[4]. The DE mesh is an assembly of rigid nonoverlapping spherical elements. Note that the DE elements do not represent the constituents of concrete. The DE model we use aims at reproducing only the macroscopic behaviour of 
concrete. The number of cohesive links varies from a DE to another. An average number of interactions is defined by adjusting the interaction range to ensure an isotropic DE packing.

The elastic normal and tangential (shear) links stiffnesses are identified from macroscopic elastic parameters (Young's modulus and Poisson's ratio) by using a "micro-macro" relation inspired from homogenization models [2]-[4], [6], [9]-[11]. The behaviour of undamaged concrete is assumed to be linear, elastic, isotropic and homogeneous. DE interactions are modelled as beam-like elements with a non-linear constitutive behaviour to model damage in tension, and compaction (closure of porosity) under high pressure compression. The strain rate sensitivity is taken into account in tension by increasing link resistance under moderate and high rate loadings. The non-linear parameters of the model are identified thanks to simulation of laboratory tests (unconfined compression, tension, confined compression and spalling tests) [7], [12]-[15].

\subsection{Concrete-steel modelling}

Common beam-like finite elements are used to represent the steel reinforcement allowing to easily model complex grids of rebars in real-scale reinforced concrete structures. A special concrete-steel bond model is developed by Potapov et al. [6] to represent interactions between the concrete spherical DE and the steel FE. This model describes interaction between a given rebar and a group of neighbouring discrete elements by using two non-linear springs, one normal and one tangential to the direction of the rebar. The behaviour of the normal spring is elasto-plastic in compression and brittle in tension, whereas the tangential one relies on the response of the concrete-steel link observed in pull-out tests.

\section{SIMULATION OF AN EDGE-ON IMPACT TEST}

\subsection{Experimental setup}

To check the reliability of the plain concrete DE model accounting for the strain rate dependency, the edge-on impact test from [7] is simulated. In this experiment (Fig. 1), a thin concrete tile $\left(20 \times 12 \times 1.5 \mathrm{~cm}^{3}\right)$ is impacted by a cylindrical ogive-nose projectile $(\mathrm{d}=1.99 \mathrm{~cm}, \mathrm{~h}=6.2 \mathrm{~cm})$. Two rigid plates constrain the vertical displacements of the top and bottom specimen faces, whereas a flexible vertical plate with fixed ends limits the horizontal displacement of the rear face of the tile.
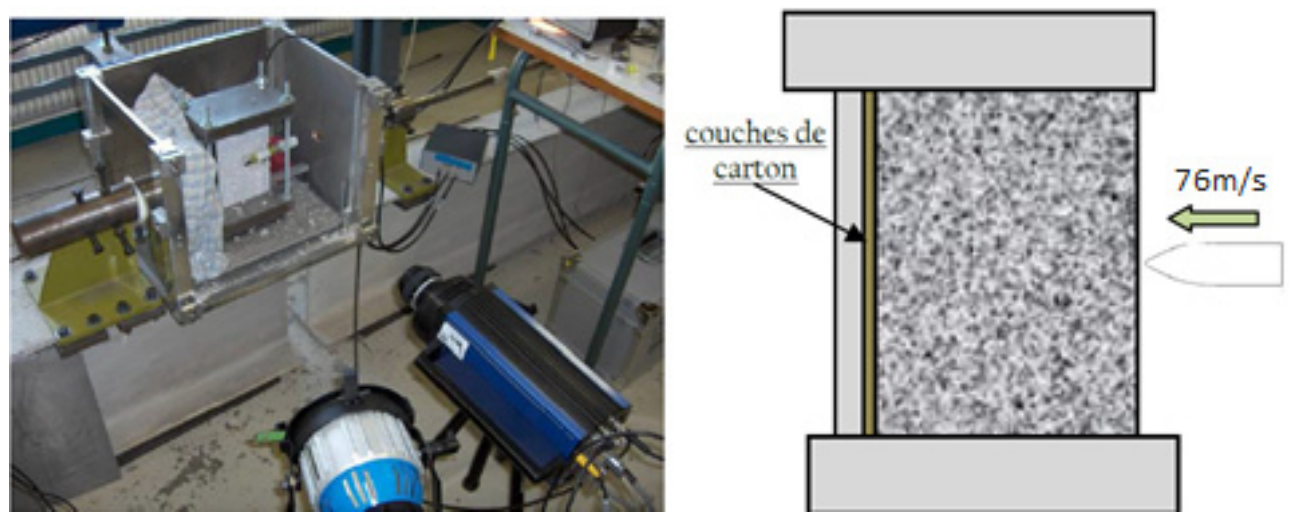

Figure 1: Edge-on impact setup. 


\subsection{Edge-on-impact modelling}

Fig. 2 shows the DEM/FEM model of the edge-on-impact test. DE are used to model the concrete specimen. Hexahedral FE are used for the support plates and tetrahedral FE for the projectile. The DE mesh is composed of 118,209 elements $\left(R_{\min }=0.47 \mathrm{~mm}, R_{\max }=\right.$ $1.41 \mathrm{~mm})$.

\subsection{Calibration of parameters}

The specimen is made of fully saturated unreinforced ordinary concrete R30A7, whereas the supports and the projectile are in rigid steel $\left(\sigma_{\mathrm{y}}=1,500 \mathrm{MPa}\right)$. R30A7 concrete was broadly investigated in previous studies with quasi-static (compressive, tensile), high compressive pressures and dynamic tensile (moderate and high strain rate) experiments [7], [11]-[14]. For the DE all the parameters are calibrated to represent macroscopically R30A7's behaviour. First, the linear behaviour parameters are identified from Young's Modulus ( $E=25 \mathrm{GPa}$ ) and Poisson's ratio $(v=0.16)$, followed by the non-linear behavior parameters identified to reproduce tensile strength $\left(\sigma_{\mathrm{T}}=3.4 \mathrm{MPa}\right)$ and compressive strength $\left(\sigma_{\mathrm{C}}=34 \mathrm{MPa}\right)$. The parameters for high compressive pressures are calibrated on hydrostatic and oedometric tests, while the strain rate sensitivity parameters are identified on spalling test. The analytical procedure and the parameters for the plain fully saturated concrete are fully described in the paper by Antoniou et al. [16].

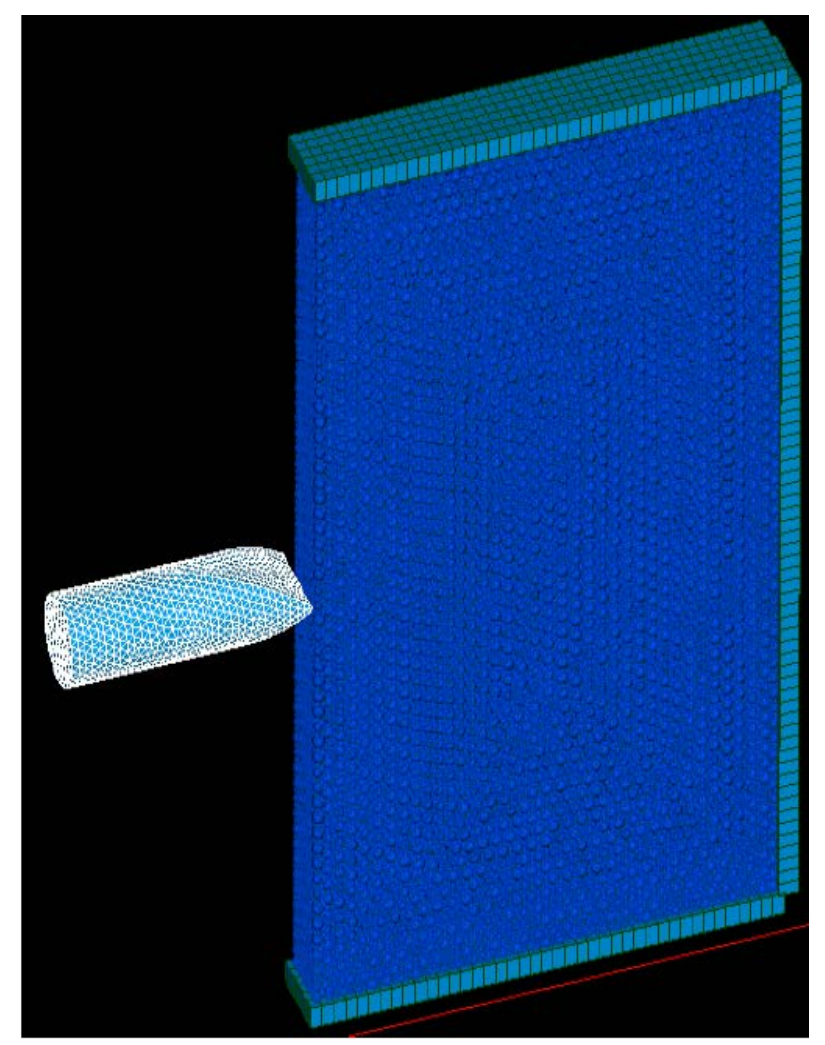

Figure 2: Edge-on impact DEM/FEM model. 


\subsection{Numerical results}

Fig. 3 shows the final damage stage of the edge-on-impact experimental. The results from the numerical simulation, shown in Fig. 4, are in good agreement with the experiment especially for the cratering damage mode. The calculated penetration depth of the missile corresponds to the measured one as can be seen in Fig. 5.

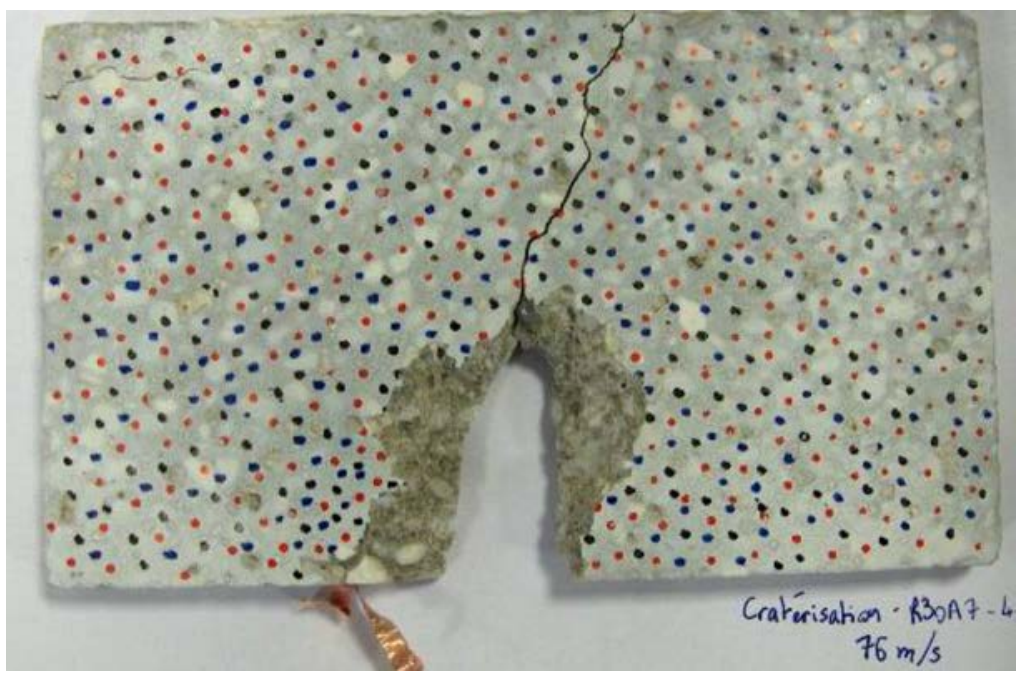

Figure 3: Edge-on impact final damage state (experiment).

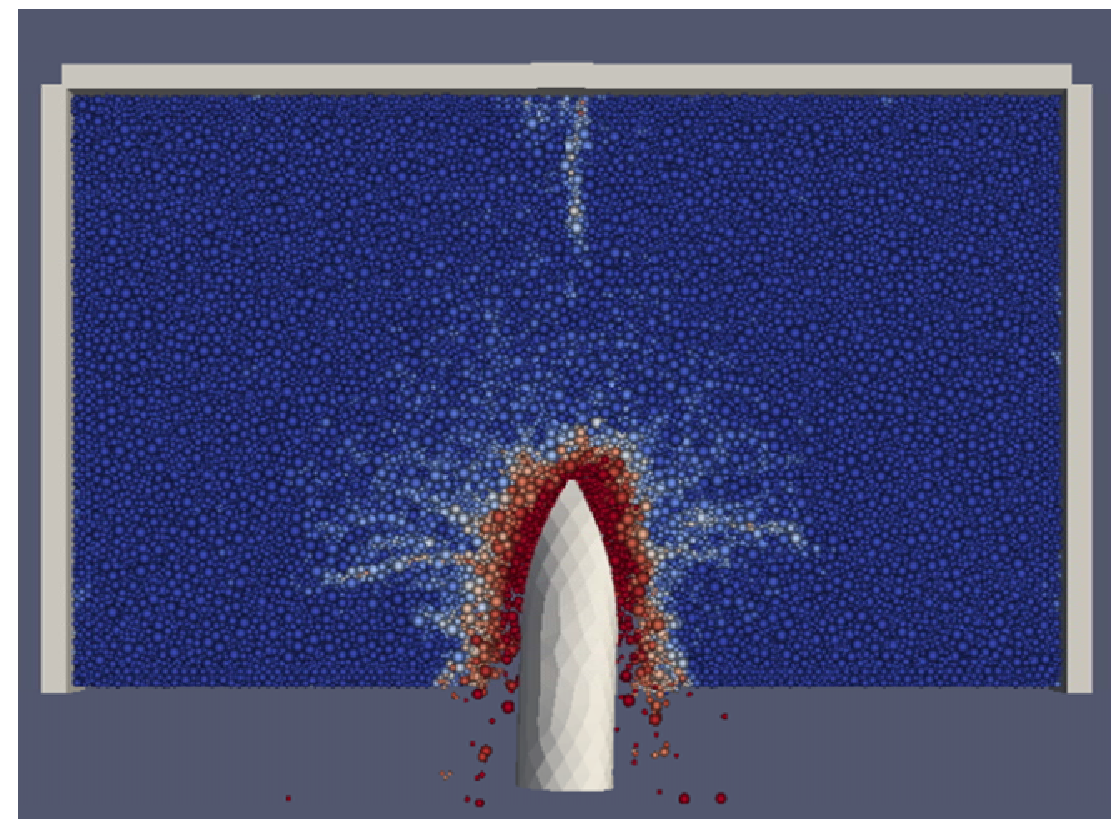

Figure 4: Edge-on impact final damage state (simulation). 


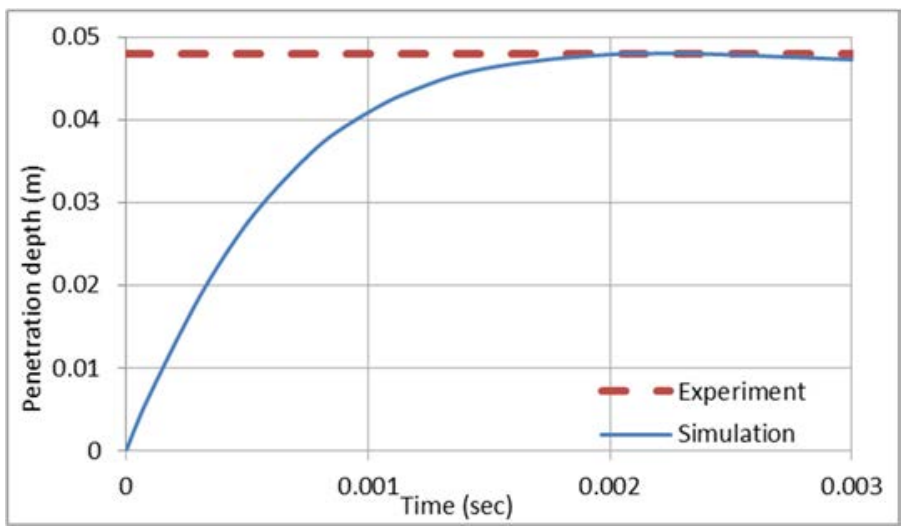

Figure 5: Projectile's penetration depth.

\section{SIMULATION OF A DROP-WEIGHT IMPACT ON A RC CONCRETE BEAM}

\subsection{Test description}

To show the capability of the developed approach to represent very advanced damaged states of RC structures under severe dynamic loading, we simulated the SSOb test from an experimental program conducted in 2007 by the University of Toronto [8]. The aim of these experiments was to produce experimental data for hard impacts by testing large RC beam specimens under free falling drop-weights (Fig. 6).

The SSOb beam was doubly-reinforced with four longitudinal bars No. 30 having $30 \mathrm{~mm}$ diameter and $700 \mathrm{~mm}^{2}$ cross section. The bars were placed symmetrically along the height in order to have the same resistance properties of the beam in positive and negative bending and they spanned the entire length of the beam. In the considered SSOb test no transverse reinforcement was used that maximized damage. The beam was simply supported as shown in Fig. 6. However, to prevent uplift of the beam from the supports during the impact an arrangement with four No. 30 support bars was used holding the beam down. At the bottom end these vertical bars were fitted to spherical bearings to enable free rotation, whereas at the top they were fixed to a structural steel section with a hinge allowing the beam to rotate freely at the supports.

The concrete used for the beam was an ordinary concrete with $10 \mathrm{~mm}$ aggregate size. During the casting of the beams several standard cylinder samples $(150 \mathrm{~mm}$ in diameter and $300 \mathrm{~mm}$ in height) were created to determine the compressive strength of the concrete. The age of the beam specimens and the cylinders samples was more than one year at the time of impact testing. The compressive peak stress measured on the cylinders was $50.1 \mathrm{MPa}$ and the strain at peak stress was 0.0023 .

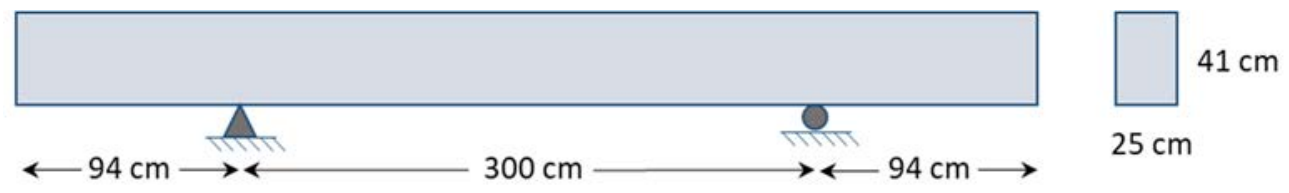

Figure 6: Specimen dimensions. 
The standard prisms $(152 \times 153 \times 508 \mathrm{~mm})$ were tested to determine the tensile coupon strength of the concrete. The direct tensile strength for 1 year dried specimen was estimated at 3.2 MPa. Standard tensile tests were carried out to determine the properties of the steel reinforcement (Table 1).

The densities of concrete and the steel bars were also been measured by weighting the samples and the bars (Table 2).

A heavy drop-weight of $600 \mathrm{~kg}$ was used for the testing. It was manufactured by filling a $300 \mathrm{~mm}$ square HSS (hollow structural steel) section with concrete and adding thick steel plates welded to the HSS section. The weight was hung on the crane by a nylon rope that was cut resulting in the fall of the weight on the specimen. Two I-shaped steel column were used to guide the weight and ensure hitting the right point on the beam. A $30 \mathrm{~mm}$ clearance between the weight and the flanges of the columns excluded any friction during the fall. To obtain a well-distributed impact force, a $50 \mathrm{~mm}$ thick $300 \mathrm{~mm}$ square steel plate was placed on the beam in the impact point. The weight was dropped from the clear height of $3.26 \mathrm{~m}$ above the specimen resulting in an impact velocity of $8 \mathrm{~m} / \mathrm{s}$.

The drop-weight punched through and caused massive concrete spalling both at the top and the bottom of the beam (Fig. 7).

The longitudinal reinforcing bars were exposed and severely bent. There were also signs of bond failure of the reinforcement bars at the supports. One distinctive result was the formation of a shear plug with major diagonal cracks starting at the top from the impact point and propagating downwards with an angle of approximately $45^{\circ}$. Because SSOb test had no stirrups, the middle segment punched through with almost no visible bending deformations. In addition, several diagonal cracks parallel to the major shear-plug cracks also developed as well as some bending cracks at the mid-span and at the supports. Another diagonal crack developed alongside the shear plug starting from the supports and becoming horizontal close to the top before reaching the impact zone. As indicated in the test report, the flexural behaviour of the beam was minimal.

Table 1: Steel coupon test results.

\begin{tabular}{|c|c|c|c|}
\hline Yield strain $\left(\times 10^{-3}\right)$ & Yield stress & Ultimate strength & Modulus of elasticity \\
\hline 2.38 & $464 \mathrm{MPa}$ & $630 \mathrm{MPa}$ & $195 \mathrm{GPa}$ \\
\hline
\end{tabular}

Table 2: Material densities.

\begin{tabular}{|c|c|}
\hline Material & Density \\
\hline Concrete (SSOb) & $2,437 \mathrm{~kg} / \mathrm{m}^{3}$ \\
\hline Steel (No. 30 bar) & $5.3 \mathrm{~kg} / \mathrm{m}$ \\
\hline
\end{tabular}
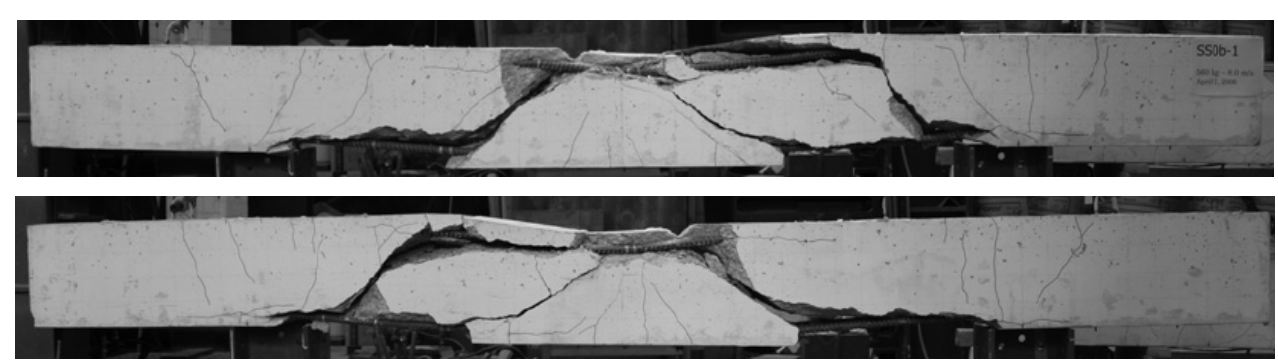

Figure 7: Final photographs of front and back faces for SSOb test. 


\subsection{Modelling with EUROPLEXUS code}

\subsubsection{Setup model}

To model the experimental setup, a detailed numerical model is built (Fig. 8). Standard FEM is used to model the longitudinal steel reinforcement, the upper and lower support plates, the anti-uplift bars, the impactor and a square steel plate inserted under the drop weight. The DE modelling is used for concrete. The DE mesh contains 60,488 elements $\left(R_{\min }=5.95 \mathrm{~mm}\right.$, $\mathrm{R}_{\max }=1.78 \mathrm{~cm}$ ). To account for increased resistance of concrete under hard-type impact, the local strain-rate dependency is used. Unilateral contact conditions are prescribed everywhere between the DE and FE parts of the model. Steel-concrete bond laws presented in [6] are applied to describe the interaction between the concrete and the steel reinforcement. The friction coefficient of 0.5 is used for steel-concrete contact, and 0.3 for steel-steel contact. Gravity is taken into account for the whole DE/FE model.

\subsubsection{Calibration of parameters}

Starting from the macroscopic parameters of concrete, linear and nonlinear material parameters of the DE model were calibrated with the help of specially developed automatic procedures, which involve a series of EUROPLEXUS calculations with automatic testing and changing of parameters. Calibration in tension and compression is made on prism-type DE specimens.

Before simulating the SSOb test, we apply the set of parameters obtained by calibration to simulate the standard compression test on cylinder, and compare the numerical results with the measures realized in [8] on concrete cylinders. In this test, the cylinder is compressed very slowly by two rigid steel plates until its full ruin. We simulate this test by modelling frictional contact between the steel plates and the DE model of cylinder. Fig. 9 shows the damage state of the cylinder for different strain levels. As can be seen the concrete near the cylinder ends is not damaged because they are constrained by friction. A barrel-type deformation of the DE model is conforming to experimental observation.

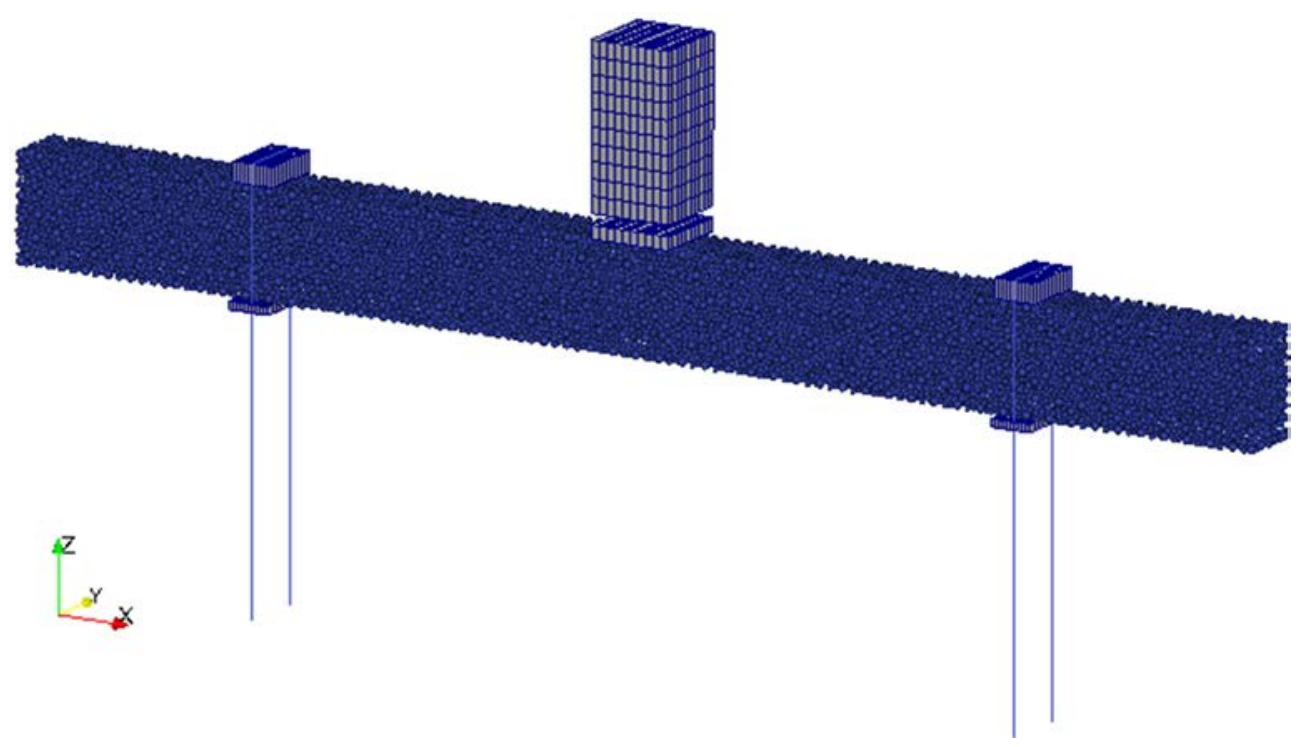

Figure 8: View of the DE/FE model. 


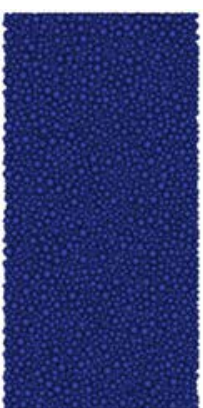

a)

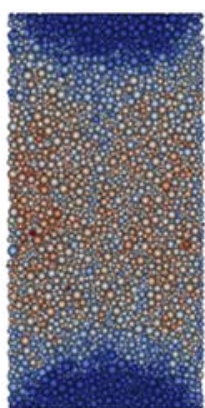

b)

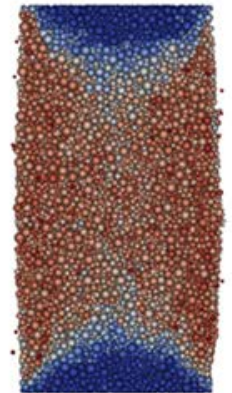

Damage level

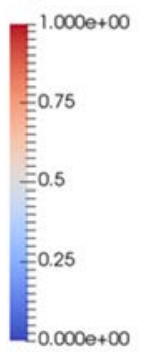

c)

Figure 9: Damage state of the cylinder. (a) Initial state; (b) For $\varepsilon=0.2 \%$; (c) For $\varepsilon=0.6 \%$.

The stress-strain curve obtained in this simulation is shown in Fig. 10. Stress is obtained by dividing the reaction force at the plates by the initial cross-section area of the cylinder, whereas the strain is calculated from the plates' displacements and the initial height of the cylinder. Both the trend of the curve and the peak value are correctly reproduced.

\subsubsection{Numerical results for SSOb test}

Then, the drop-weight test was simulated. Fig. 11 shows evolution of damage of the RC beam for five consecutive time stations.

It should be noted that damage is defined at each time step as a ratio of remaining cohesive links of the considered DE over the initial number of its cohesive links. Thus, this kind of damage indicator allows detecting zones of material degradation but cannot attest definitively to the presence of macro-cracks. For the considered case the real material discontinuities can be seen when plotting the vertical displacement field (Fig. 12). The basic colour changes reveal the presence of at least three oblique macro-cracks delimiting different material fragments. These are in good agreement with the macro-cracks observed in the experiment (Fig. 7).

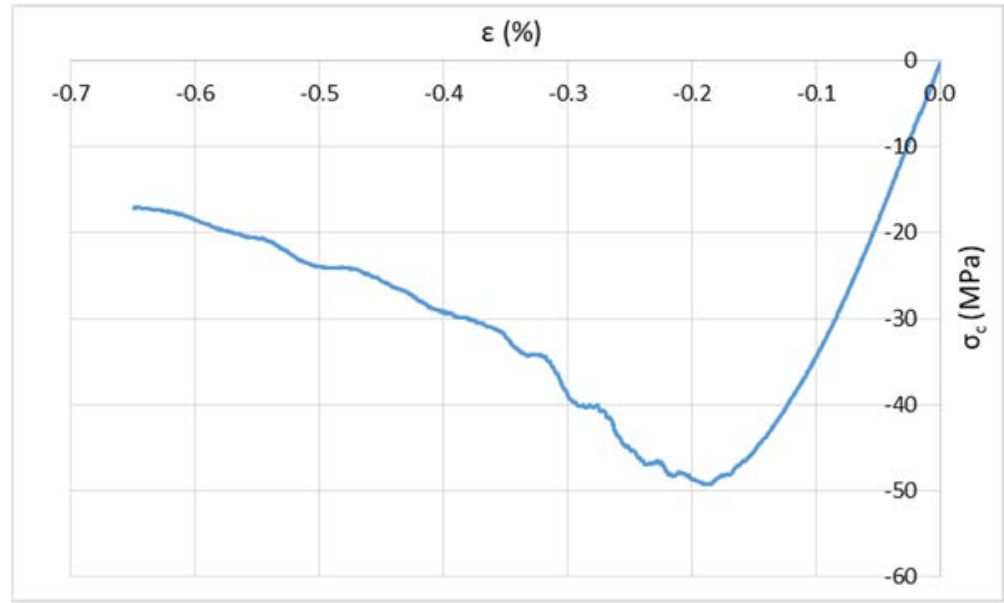

Figure 10: Stress-strain curve in the cylinder compression test simulation. 


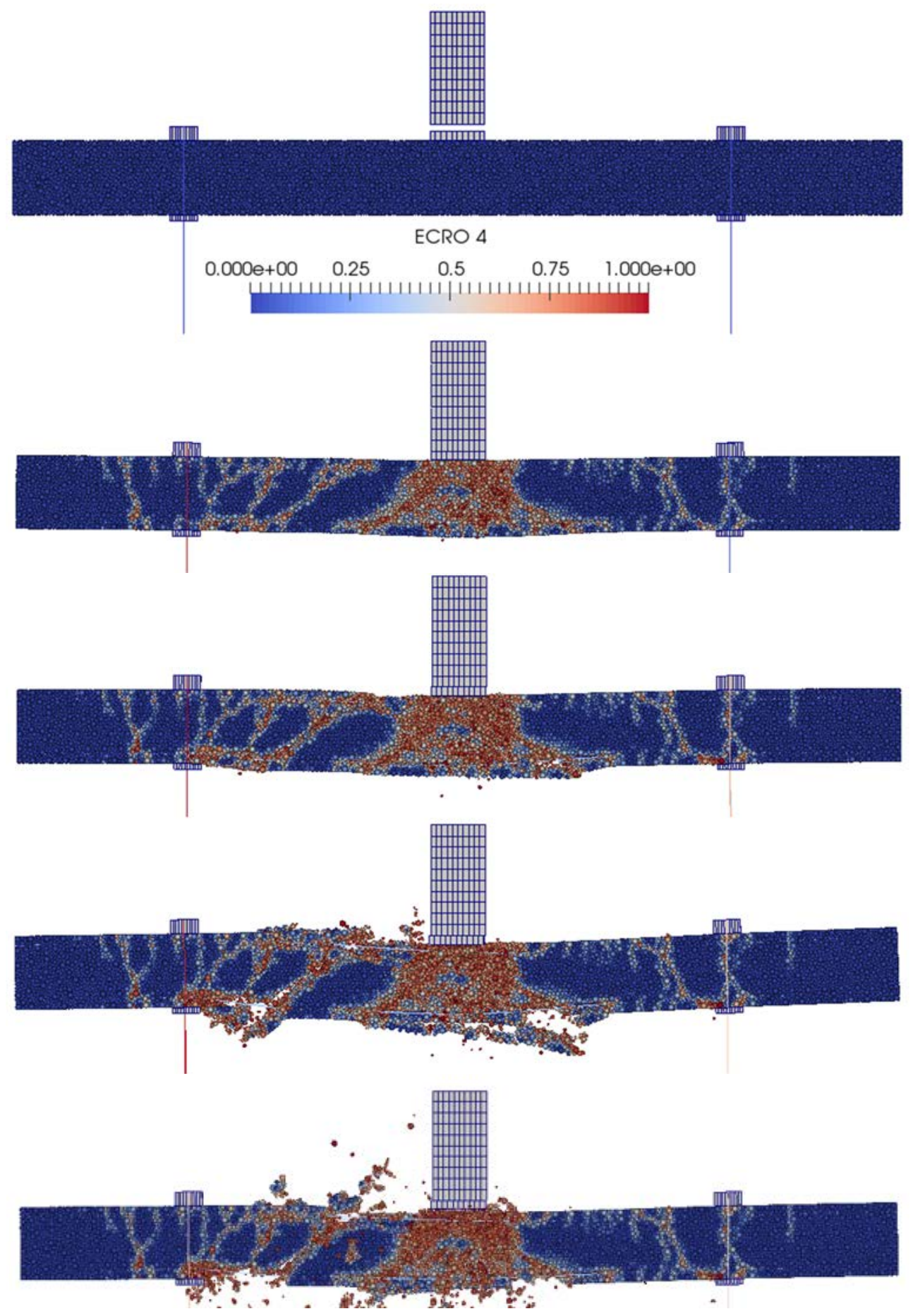

Figure 11: Damage state of concrete at $\mathrm{t}=0,10 \mathrm{~ms}, 20 \mathrm{~ms}, 50 \mathrm{~ms}$, and $200 \mathrm{~ms}$ (from top to bottom). 


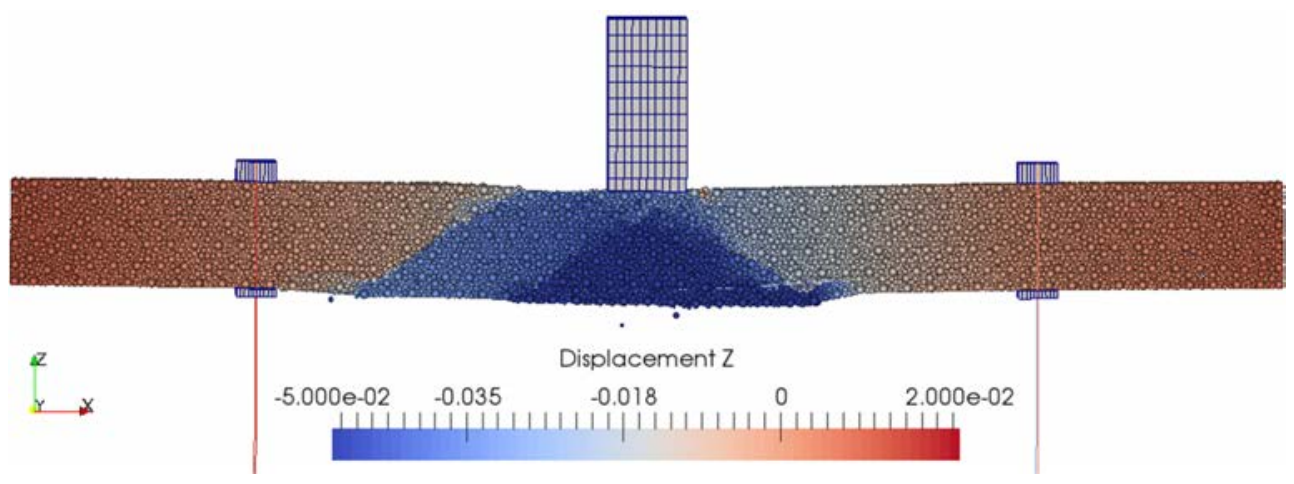

Figure 12: Vertical displacement $U_{Z}$ at $17 \mathrm{~ms}$.

Because the explicit-type time integration algorithm was used for this analysis, it is difficult to produce a fully static solution corresponding to the final state of the experiment. As can be seen in Fig. 13, the beam has resisted to the first impact and not completely failed, but several oscillation periods are needed to completely dissipate the impact energy and obtain the final crack opening due to the drop-weight gravity action.

Analysis of the results obtained in the simulation of SSOb impact test shows that the main physical phenomena observed in the experiment are correctly represented by the mixed DEM/FEM model.

\section{CONCLUSION}

In this study a mixed DEM-FEM approach is applied to simulate hard-type impacts on plain and reinforced concrete specimens. The edge-on-impact test of a rigid missile on a very thin concrete specimen was simulated to verify the reliability of the strain rate dependency constitutive law on plain concrete. The numerical results are in good agreement with the experiment especially for the cratering damage mode and penetration depth of the missile. Then, mixed DEM-FEM model was used to simulate the advanced damaged state of a large reinforced concrete beam under a drop-weight impact. The crack patterns predicted by the

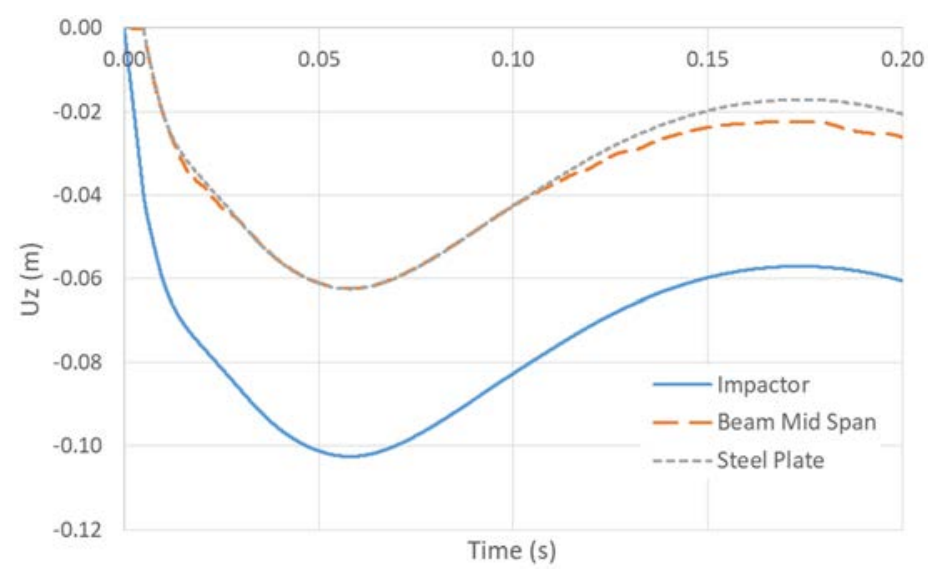

Figure 13: Vertical displacements versus time in simulation. 
simulation are in very good agreement with the post-mortem state of the beam observed in the experiment.

Thus, the missile penetration depth for the plain concrete test and vertical deflection and fractured state for the RC beam are thoroughly reproduced. These results show that the DEMFEM model seems to be ready for simulation of industrial-size reinforced concrete structures severe accidental loadings.

\section{REFERENCES}

[1] EUROPLEXUS, A computer program for analysis of fast transient phenomena involving structures and fluids in interaction. www-epx.cea.fr.

[2] Hentz, S., Daudeville, L. \& Donzé, F.V., Identification and validation of a discrete element model for concrete. Journal of Engineering Mechanics, 130(6), pp. 709-719, 2004.

[3] Hentz, S., Donzé, F.V. \& Daudeville, L., Discrete element modelling of concrete submitted to dynamic loading at high strain rates. Computers \& Structures, 82(29-30), pp. 2509-2524, 2004.

[4] Daudeville, L. \& Malécot, Y., Concrete structures under impact. European Journal of Environmental and Civil Engineering, 15(supp. 1), pp. 101-140, 2011.

[5] Jerier, J.F., Imbault, D., Donze, F.V. \& Doremus, P., A geometric algorithm based on tetrahedral meshes to generate a dense polydisperse sphere packing. Granular Matter, 11(1), pp. 43-52, 2009.

[6] Potapov, S., Masurel, A., Marin, P. \& Daudeville, L., Mixed DEM/FEM modeling of advanced damage in reinforced concrete structures. Journal of Engineering Mechanics, 143(2), 04016110, 2016.

[7] Forquin, P. \& Erzar, B., Dynamic fragmentation process in concrete under impact and spalling tests. International Journal of Fracture, 163(1-2), pp. 193-215, 2010.

[8] Saatci, S., Behaviour and modelling of reinforced concrete structures subjected to impact loads. PhD thesis, University of Toronto, 2007.

[9] Frangin, E., Marin, P. \& Daudeville, L., On the use of combined finite/discrete element method for impacted concrete structures. Journal de Physique IV (Proceedings), 134, pp. 461-466, 2006.

[10] Rousseau, J., Frangin, E., Marin, P. \& Daudeville, L., Damage prediction in the vicinity of an impact on a concrete structure: a combined FEM/DEM approach. Computers and Concrete, 5(4), pp. 343-358, 2008.

[11] Omar, A., Marin, P., Potapov, S. \& Daudeville, L., 3D discrete element modeling of concrete: Study of the rolling resistance effects on the macroscopic constitutive behaviour. Proceedings of the XII International Conference on Computational Plasticity-Fundamentals and Applications, COMPLAS XII, Barcelona, 2013.

[12] Gabet, T., Malécot, Y. \& Daudeville, L., Triaxial behaviour of concrete under high stresses: Influence of the loading path on compaction and limit states. Cement and Concrete Research, 38(3), pp. 403-412, 2008.

[13] Vu, X.H., Malecot, Y. \& Daudeville, L., Strain measurements on porous concrete samples for triaxial compression and extension tests under very high confinement. The Journal of Strain Analysis for Engineering Design, 44(8), pp. 633-657, 2009.

[14] Malecot, Y., Daudeville, L., Dupray, F., Poinard, C. \& Buzaud, E., Strength and damage of concrete under high triaxial loading. European Journal of Environmental and Civil Engineering, 14(6-7), pp. 777-803, 2010. 
14 Structures Under Shock and Impact XV

[15] Antoniou, A., Contribution to the experimental analysis and numerical modelling of spalling technique into concrete specimens under dynamic tension. Master's thesis, Université Joseph Fourier, 2014.

[16] Antoniou, A., Daudeville, L., Marin, P., Omar, A. \& Potapov, S., Discrete element modelling of concrete structures under hard impact by ogive-nose steel projectiles. European Physical Journal ST, in press. 